This item is the archived peer-reviewed author-version of:

\title{
The role of an ARM procedure is the prevention of breast cancer related lymphedema
}

\section{Reference:}

Tjalma Wiebren, Verbelen Hanne, Gebruers Nick.- The role of an ARM procedure is the prevention of breast cancer related lymphedema

European journal of surgical oncology - ISSN 0748-7983 - (2015), p. 1-2

Full text (Publishers DOI): http://dx.doi.org/doi:10.1016/j.ejso.2015.09.028

Handle: http://hdl.handle.net/10067/1290990151162165141 


\section{Accepted Manuscript}

The role of an ARM procedure is the prevention of breast cancer related lymphedema

W. Tjalma, H. Verbelen, N. Gebruers

PII: S0748-7983(15)00839-2

DOI: $\quad$ 10.1016/j.ejso.2015.09.028

Reference: $\quad$ YEJSO 4190

To appear in: European Journal of Surgical Oncology

Received Date: 2 September 2015

Accepted Date: 3 September 2015

Please cite this article as: Tjalma W, Verbelen $\mathrm{H}$, Gebruers $\mathrm{N}$, The role of an ARM procedure is the prevention of breast cancer related lymphedema, European Journal of Surgical Oncology (2015), doi: 10.1016/j.ejso.2015.09.028.

This is a PDF file of an unedited manuscript that has been accepted for publication. As a service to our customers we are providing this early version of the manuscript. The manuscript will undergo copyediting, typesetting, and review of the resulting proof before it is published in its final form. Please note that during the production process errors may be discovered which could affect the content, and all legal disclaimers that apply to the journal pertain. 
The role of an ARM procedure is the prevention of breast cancer related lymphedema

W. Tjalma ${ }^{1,2}$, H. Verbelen ${ }^{1,3}$ N. Gebruers ${ }^{1,2,3}$

1 Multidisciplinary Breast Clinic, Antwerp University Hospital

2 Faculties of Medicine and Health Sciences, University of Antwerp

3 Faculties of Medicine and Health Sciences, department of rehabilitation sciences and physiotherapy, University of Antwerp

Key-words: Breast cancer, Sentinel node, axillary reverse mapping, morbidity, lymphedema

We read with interest the statement of Rutgers and Donkers that there is hardly a role for the Axillary Reverse Mapping (ARM) procedure in current modern management of the axilla of breast cancer patients. ${ }^{1,2}$

The actual indication for an ARM procedure in breast cancer is to preserve the lymphatic drainage from the arm. The ARM procedure should limit the invasiveness in the axilla during breast cancer surgery when looking for the sentinel node (SN). The ARM procedure maps the lymphatic draining of the arm into the axilla. The lymphatic draining of the arm is normally not the same lymphatic pathway as from the breast. When visible, the surgeon can spare these lymphatics during lymph node(s) surgery; limiting the possibility of breast cancer related lymphedema (BCRL). The majority of the ARM lymph nodes are located above the second intercostal brachial nerve (ICBN) and the majority of the SNs are located below the ICBN. There is cross-over between ARM and SN in about $15 \%$ (range $0 \%-28 \%$ ). ${ }^{2}$ It is not the goal of the ARM procedure to replace the SN procedure. The purpose of the ARM procedure is to guide you in the dissection. It allows you to be more careful in critical areas along side the long thoracic nerve, the thoracodorsal nerve, the medial and the lateral pectoral nerves and the intercostobrachial nerve. This will lead to a further reduction in morbidity related to surgery. The morbidity related to axillary surgery has dropped considerable when the SN replaced the conventional axillary clearance. But 
the morbidity after the removal of only a sentinel node cannot be neglected. The overall incidence of lymphedema in patients with sentinel node-negative breast cancer ranged from $0 \%$ to $63.4 \%{ }^{3}$ Even after two years women with a negative SN complain of pain (range 5.6-51.1\%), numbness (range 5.1-51.1\%), loss of strength (range 0-57.7\%), decreased internal rotation (44.4\%), and decreased abduction (range $0-41.4 \%) .{ }^{4} \mathrm{~A}$ recent analysis revealed that complains still exist after 7 years (submitted). A further reduction in the morbidity by refining the surgery would be warmly welcomed.

Additionally the mapping procedure has other advantages that have to be explored. For instance, a goal could be to identify the location of the disrupted lymphatic drainage after the surgery. Theoretically women with a disrupted drainage of the arm have an increased risk of developing lymphedema. A randomized control trial should be done in which half of the patients with a disrupted drainage will have a dedicated physiotherapeutic program to prevent lymphedema and the other half will have the standard of care. By this means you hope to identify women at high risk and you can provide them special care. Currently we are looking at the role of fluoroscopic mapping of the lymphatics in the treatment of women with chronic lymphedema.

For the above-mentioned reasons we believe that the mapping procedure does have a potential role in the current management of breast cancer patients.

\section{References}

1. Rutgers EJ, Donker M, van Tienhoven G. Is there a role for axillary reverse mapping in the current management of breast cancer treatment? Eur J Surg Oncol 2015 Jul 15. pii: S0748-7983(15)00523-5

2. Noguchi M, Miura S, Morioka E, Ohno Y, Yokoi-Noguchi M, Nakano Y, Kosaka T. Is axillary reverse mapping feasible in breast cancer patients? Eur J Surg Oncol 2015;41(4):442-9.

3. Gebruers N, Verbelen H, De Vrieze T, Coeck D, Tjalma W. Incidence and time path of lymphedema in sentinel node negative breast cancer patients: a systematic review. Arch Phys Med Rehabil 2015;96(6):1131-9.

4. Verbelen H, Gebruers N, Eeckhout FM, Verlinden K, Tjalma W. Shoulder and arm morbidity in sentinel node-negative breast cancer patients: a systematic review.

Breast Cancer Res Treat 2014;144(1):21-31. 